\title{
“Edgar Allan Poe": uma tradução comentada da crônica de Rubén Darío
}

\author{
Davi Silva Gonçalves ${ }^{1}$
}

\begin{abstract}
Resumo: Na crônica "Edgar Allan Poe" (2013), um narrador angustiado e indignado com as imagens assombrosas e, ao mesmo tempo, maravilhosas que se multiplicam ao redor dele em um passeio por Manhattan é desenvolvido pelo autor nicaraguense Rubén Darío. No texto, o cronista evidencia por que é importante falar da perspectiva não só da América hispânica, como também de uma América periférica a observar, crítica, o centro. Com um ritmo elétrico, marcado pela ausência de pausas, assim como através do uso de uma linguagem híbrida, repleta de referências hipertextuais, o texto é sufocante - da mesma forma que, para Darío, parecia ser sufocante Manhattan. Neste sentido, e para manter a confusão de estilo e imagens que faz Darío, muito provavelmente de forma proposital, minha proposta de tradução da crônica "Edgar Allan Poe" é guiada por duas premissas: 1) Promover a manutenção de sua pontuação peculiar, que preza pelo ritmo acelerado e dá ao leitor poucas oportunidades de "respirar" entre as diferentes observações que faz o narrador; 2) Reiterar o caráter híbrido e hipertextual da crônica, reproduzindo as diversas referências que Darío faz a personagens (históricos e fictícios) e a espaços, assim como seu uso de palavras em inglês, que, através do contrato de verossimilhança, convida o leitor a embarcar naquela viagem pela metrópole americana.
\end{abstract}

Palavras-chave: Edgar Allan Poe; Crônica; Tradução; Rubén Darío.

\begin{abstract}
In the personal essay "Edgar Allan Poe" (2013), an anxious narrator, haunted by images that are both gloomy and mesmerising - and that multiply around him as he strolls around Manhattan - is developed by Rubén Darío. In the text, the Nicaraguan author demonstrates why it is important not only to talk from the perspective of a Hispanic America, but also from the standpoint of a marginalised America - which observes, critically, the centre. In an electrifying
\end{abstract}

1 Mestre pelo Programa de Pós-Graduação em Inglês: Estudos Linguísticos e Literários (PPGI-UFSC); Doutor pelo Programa de Pós-Graduação em Estudos da Tradução (PGET-UFSC); Professor vinculado ao Departamento de Letras da Universidade Estadual do Centro-Oeste (UNICENTRO-PR). 
rhythm, marked by the absence of pauses, as well as through the usage of a hybrid language, filled in with hypertextual references, the text chokes the reader - so suffocating as, for Darío, Manhattan seemed to be. Therefore, and as to maintain the confusion in style and images present, probably not by chance, in the personal essay, my translation proposal of "Edgar Allan Poe" is guided by two premises: 1) The maintenance of Darío's punctuation, taking into account the accelerated flux of words that gives readers few opportunities to "breathe" between the narrator's different observations; 2) Reiterate the hybrid and hypertextual character of the personal essay, reproducing the diverse references made by Darío to historical and fictional characters, spaces, as well as his usage of words in English - choices which, through verisimilitude, invite readers to embark on that very same trip through that North American metropolis.

Keywords: Edgar Allan Poe; Personal essay; Translation; Ruben Darío

Rubén Darío, pseudônimo de Félix Rubén García (que adota o pseudônimo devido ao apreço que tinha pelo sobrenome "Darío", de um de seus avós), foi um escritor nicaraguense que nasce em Metapa (1867) e morre em León (1916). Tendo se estabelecido principalmente como poeta, Darío é tido como representante máximo e núcleo aglutinador do modernismo hispano-americano. Em seus escritos tanto poéticos quanto em prosa, é perceptível a preocupação e, ao mesmo tempo, a facilidade que o autor tinha para trabalhar com ritmo e a rima, que dão forma para sua observação perspicaz dos eventos narrados - assim como para suas elucubrações acerca de imagens por ele imaginadas. Revolucionando o verso castelhano, Darío intersecciona em seus escritos o real e o fantasioso, criando uma imagem literária híbrida, um cenário onde o possível e o impossível com frequência dialogam. Dando ao formato poético já institucionalizado um fluxo revitalizante que carrega a marca da americanidade, esse diálogo atravessa oceanos, sendo que tanto na forma quanto no tema pode-se encontrar, em seus escritos, uma Europa americanizada e uma América europeizada.

Em seu texto flexível e musical, temas universais são localizados, e os locais universalizados, sendo a analogia e a símile ferramentas literárias recorrentes para que imagens muitas vezes tradicionalmente vistas em conflito sejam trazidas para dentro da mesma arena. A ideia da arte pela arte respira por muito pouco tempo no legado do escritor já que, durante seu amadurecimento literário, o caráter social e político de seus textos se evidencia - não em dissonância com o seu viés estilístico, mas como complemento inerente dele. ${ }^{2} \mathrm{Um}$ narrador angustiado e indignado com

2 Disponível em: <http://www.biografiasyvidas.com/biografia/d/dario ruben.htm > Acesso em 09 de Setembro de 2020. 
os problemas e dificuldades que se multiplicam ao redor dele, em outros tempos e espaços, é desenvolvido por Darío - que mostra em sua escrita crítica porque é importante falar da perspectiva não só da América hispânica, como também de uma América periférica a observar, crítica, o centro. Se essa América alcança em algum momento a sua independência literária, assim como uma feição própria, muito ela deve a Rubén Darío.

Coerente com essa postura politizada e estilizada acerca do cenário social da América, nasce a crônica «Edgar Allan Poe», inicialmente proposta como prólogo para o retrato que este faz do escritor estadunidense no livro Los Raros (DARÍO, 1896). Na antologia de crônicas organizada por Graciela Montaldo e intitulada Viajes de un Cosmopolita Extremo (DARÍO, 2013), a crônica (uma versão reduzida do texto original, em cinco páginas - 129 até 133) é acompanhada por uma nota da editora que, em geral, situa este texto em particular na experiência dicotômica (ora de admiração, ora de crítica - mas, neste caso, mais ligada à última) que tem o autor com relação à modernidade. Essa modernidade que Darío observa e coloca em cheque é aquela que concerne a realidade de Manhattan, que, para ele, era muito particular. "Não é a modernidade politizada de Barcelona nem a modernidade sofisticada da cultura de Paris, senão a modernidade do dinheiro [...]" (MONTALDO, 2013, p. 30). ${ }^{3}$

Dentro dessa modernidade dinheirista, um sintoma daquilo que parecia a Darío representar os E.U.A., se multiplicam ícones monumentais e monstruosos - marcas da civilização estadunidense, mas que, aparentemente, nada fazem além de enfatizar a barbárie que é alimentada dentro dessa versão bastante questionável de civilidade. Estas são estátuas, pontes, construções onde, através do olhar do narrador criado por Darío, o gigantismo associado à síndrome de grandeza dos titãs da América é confundido com a paisagem pristina do continente. Com um ritmo elétrico, marcado pela ausência de pausas, assim como através do uso de uma linguagem híbrida, repleta de referências hipertextuais, o texto é sufocante - da mesma maneira em que, para Darío, parecia ser sufocante Manhattan. Mas o que isso tudo tem a ver com Poe? A isso responde Montaldo (2013, p. 31) quando alega que, implícita na narrativa criada por Darío na crônica, está a seguinte conclusão: "Os Estados Unidos são uma condensação do materialismo, do pragmatismo; porém também são, por outro lado, capazes de produzir poetas." Não apenas

3 "no es la politizada modernidad de Barcelona ni la modernidad sofisticada de la cultura de París, sino la modernidad del dinero [...]."

4 "Estados Unidos es una condensación del materialismo, del pragmatismo, pero a su vez es capaz de producir poetas." 
poetas, mas poetas únicos e memoráveis, como Edgar Allan Poe: grande, sufocante e louco - assim como a ilha de Manhattan.

Neste sentido, e para manter a confusão de estilo e imagens que faz Darío, muito provavelmente de forma proposital, minha proposta de tradução da crônica "Edgar Allan Poe" é guiada por duas premissas: 1) Promover a manutenção de sua pontuação peculiar, que preza pelo ritmo acelerado e dá ao leitor poucas oportunidades de "respirar" entre as diferentes observações que faz o narrador; 2) Reiterar o caráter híbrido e hipertextual da crônica, reproduzindo as diversas referências que Darío faz à personagens (históricos e fictícios), espaços, assim como sua preferência por palavras em inglês, que, através do contrato de verossimilhança, convida o leitor a embarcar naquela viagem pela metrópole americana. Naquilo que toca essa minha segunda premissa, cheguei a considerar a possibilidade de disponibilizar um glossário ou notas de rodapé para cada referência que faz Darío a textos e saberes outros. Porém, tendo em vista o caráter mundano da crônica, sua roupagem de simplicidade, proximidade e imediatismo, acabei por desistir da ideia - motivado também por meu interesse em manter a confusão promovida pelas imagens que se sobrepõem umas às outras no texto de Darío ("solucionar" essa confusão através de notas, talvez, seria pouco frutífero para este fim). Essas referências externas, portanto, não são destrinchadas ao longo do texto traduzido, mas são aqui, antes dele, destacadas - se meu leitor quiser se manter confuso, sugiro que pule as próximas páginas, direto para a crônica.

Os hipertextos podem ser divididos como estando inseridos em quatro distintos gêneros: 1) Personagens históricos e fictícios; 2) Lugares; 3) Aspectos culturais localizados no âmbito da América hispânica e/ou dos Estados Unidos; 4) Estrangeirismos. O primeiro personagem histórico é, talvez, também o mais óbvio: Edgar Allan Poe (1809-1849), renomado poeta e contista (tendo sido um dos primeiros estadunidenses que se dedica com tanto afinco a esse gênero) que marcou o movimento romântico dos Estados Unidos. Contribuindo, com seu estilo gótico diretamente para o surgimento de um conceito de ficção científica, suas estórias marcadas pelo horror, macabro e sombrio são até hoje consumidas por um vasto número de leitores. ${ }^{5}$ Menos conhecido, Paul Groussac (18481929) foi um escritor "franco-argentino". Apesar de nascer em Toulouse, chega à Buenos Aires com apenas dezoito anos e lá permanece, se tornando professor da Escuela Normal de Tucumán (1878) e posteriormente, em 1885, diretor da Bi-

5 Disponível em: $<$ http://encyclopedia2.tfd.com/Edgar+Allan+Poe $>$ Acesso em 09 de Setembro de 2020. 
blioteca Nacional. Marcado por um alto espírito crítico, os mais famosos textos de Groussac são seus relatos de viagem, nos quais ele descreve suas experiências em espaços outros que Buenos Aires. ${ }^{6}$ Mais à frente em seu texto Darío menciona Thomas Edison (1847-1931), responsável por diversas invenções cruciais para a modernização do cenário da vida urbana - entre elas a lâmpada elétrica, estrada de ferro eletromagnética, câmera cinematográfica, bateria de carro e a embalagem a vácuo. ${ }^{7}$

Outro personagem que permeia a narrativa de Darío, em diversos momentos distintos, consiste no escritor mais importante da literatura não só britânica, mas em língua inglesa: William Shakespeare (1564-1616). Essa menção ocorre ora de maneira direta, quando Darío diz o nome Shakespeare com todas as letras, ora de forma indireta, quando ele preenche sua crônica com aspectos da peça The Tempest (1610-11), assim como com boa parte de seus personagens - a citar: Calibã, Próspero, Sycorax, Peladan e Miranda. A peça trágica se passa em uma ilha (como Manhattan) remota (ao contrário de Manhattan) onde Próspero, o Duque de Milão, cria um plano para resgatar sua filha Miranda através de estratégias ilusionistas - principalmente conjurando uma tempestade, daí o título da peça. Apesar de ter sido enganado por seu irmão Antônio, que o coloca em um barco fadado ao naufrágio, o maior antagonista de Próspero é o personagem Calibã, um selvagem (aparentemente o único de sua espécie), meio homem meio monstro, natural da ilha onde a estória se passa. O embate principal se dá porque Calibã tenta estuprar Miranda para povoar a ilha, intento que, para Próspero, justificaria qualquer crueldade que fosse praticada contra o "selvagem".

Derrotado por Próspero, Calibã, que posteriormente descobrimos ser filho de Sycorax, é por ele escravizado. Sycorax, exilada, havia sido deixada na ilha grávida de Calibã com um demônio - apesar desta morrer antes de sua chegada na ilha. Isto sabemos pois a plateia e/ou leitores da peça têm acesso a uma série de memórias de Sycorax, que explicam o que acontece antes do início da estória. Ao tomar conhecimento de sua origem, Calibã alega que a ilha lhe pertence de direito (já que sua mãe parece ter sido a primeira habitante dela) e que a sua escravização não seria justa - mas nunca consegue se livrar por muito tempo da condição de

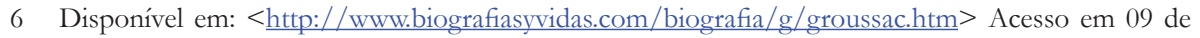
Setembro de 2020.

7 Disponível em: < http://encyclopedia.thefreedictionary.com/thomas+edison $>$ Acesso em 09 de Setembro de 2020. 
servo antes somente de Próspero e depois de Próspero e Miranda. ${ }^{8}$ Trata-se este de um aspecto da narrativa que tem permitido uma série de releituras na contemporaneidade através de lentes críticas pós-coloniais, feministas e da teoria queer. Shakespeare escrevia em um período no qual muitas estórias do Novo mundo chegavam na Europa e é bem provável que a peça, principalmente naquilo que tange a figura de Calibã, tenha relação com essas estórias (mais especificamente, tendo em vista o nome do personagem, com os relatos sobre o Caribe e/ou os canibais). Sendo este um texto que lida consistentemente com a relação selvagem/civilizado, de uma perspectiva moral e repleta de ingredientes coloniais, sua transformação em um hipertexto na crônica de Darío é significativa para pensarmos nessa analogia entre o mundo da tempestade e o mundo da metrópole estadunidense; esse mundo no qual nasce Edgar Allan Poe.

Entretanto, não é apenas na referência que faz Darío a peça Shakespeariana que reside essa imagem do selvagem e do demônio, sendo ela reiterada em diversos momentos do texto - principalmente ao final dele. Já nos últimos parágrafos o cronista faz uma alusão a bíblia, a um trecho específico no qual Jesus tenta exorcizar um demônio - que na verdade são vários demônios - do corpo de um andarilho. “Jesus o interrogou: 'Qual é o teu nome?’ Respondeu ele: 'Meu nome é Legião, porque somos muitos’. E implorava insistentemente para que Jesus não os mandasse para fora daquela região" (Marcos 5: 9). ${ }^{9}$ Essa alusão, que lembra o trecho bíblico de exorcização de um grupo imenso de espíritos do mal de um corpo, apenas serve bem o fim de expandir a ideia de barbárie. O exército de Calibãs que ocupa a crônica de Darío, que se chama legião, são figuras alegóricas, porém selvagens e endemoniadas - são centenas delas, que também ocupam o espaço pequeno de um corpo: neste caso de uma ilha. Existe, é bem verdade, uma referência robusta a esse mesmo trecho bíblico na contemporaneidade; trata-se do romance O Meu nome é Legião (2007), do escritor português Antonio Lobo Antunes. Curiosamente, muitos paralelos podem ser estabelecidos não só entre as referências já existentes como também com aquelas que nascem no momento pós-texto (depois de Darío ter publicado sua crônica). É este, indubitavelmente, o caso do livro de Lobo Antunes, um claro exemplo dessa referencialidade póstuma, já que boa parte de sua narrativa dialoga com Darío - e até mesmo com

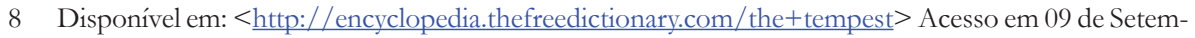
bro de 2020.

9 Disponível em: < https://www.bibliaonline.com.br/acf/busca?q=legi $\%$ C3\%A3o $>$ Acesso em 09 de Setembro de 2020. 
Shakespeare - principalmente naquilo que concerne o protagonismo do espaço narrativo em questão. ${ }^{10}$

Da mesma forma, outras referências, que nos remetem a tempos até mesmo mais antigos do que aquele de Shakespeare (ainda que estejamos tratando de um texto claramente moderno, e que lida com aspectos da modernidade), podem ser encontradas na crônica de Darío. Entre elas temos a referência à deusa romana da caça, da lua e da fertilidade, Diana - um dos símbolos maiores da feminilidade e do feminismo, sendo que, assim como Minerva e Vesta, faz o juramento de que nunca se casaria. ${ }^{11} \mathrm{Na}$ mitologia, Diana é associada com os animais selvagens (de novo o selvagem) e com cenários e atributos gerais da natureza, madeira, montanhas etc. Equivalente da Deusa Artêmis, ainda que sua origem seja relativamente independente, Diana foi adorada na Roma antiga e também o é durante o neopaganismo. Outra deusa - dessa vez grega - a quem Darío faz menção é Hécate, deusa dos fantasmas e da bruxaria. Originalmente ligada às três Deusas Selene, nos céus; Artêmis, na terra; e Perséfone, no submundo, Hécate se distancia não só delas como também de seu uso do poder para fins benevolentes. ${ }^{12}$ Se estabelecendo como uma deusa das trevas, Hécate prefere, ao invés disso, conjurar os espíritos dos mortos através da magia negra, assombrando cemitérios e estradas isoladas.

Chegamos assim à segunda categoria de referências que faz Darío, nesse caso aos lugares pelos quais ele passa durante a observação narrada em sua crônica - cuja menção serve não só para que o leitor se situe nesse espaço, como também para que este seja infectado pelo sentimento de assombro e grandeza implicado nele. São muitos os nomes de cidades/bairros (Manhattan, Nova Iorque, Brooklyn, Boston, Chicago, Washington) que aparecem no texto, por mais curto que ele seja - coerente com essa construção do narrador da crônica ${ }^{13}$ como um

10 "Esta obra retrata difusamente um conjunto de vivências do Bairro $1^{\circ}$ de Maio, um bairro de imigrantes que se situará numa zona periférica da cidade de Lisboa. Através de uma narrativa polifónica, o texto oferece-nos diferentes e contrastantes perspectivas sobre um espaço intrinsecamente pós-colonial. O que torna esta obra geograficamente interessante é o modo como se pode descobrir nela uma dualidade de representações sobre o espaço, a paisagem, as fronteiras e as territorialidades.” (PAIVA, 2013, p. 184) 11 Disponível em: < http://encyclopedia.thefreedictionary.com/Diana+mythology $>$ Acesso em 09 de Setembro de 2020.

12 Disponível em: < http://encyclopedia2.thefreedictionary.com/hecat> Acesso em 09 de Setembro de 2020.

13 Sabe-se que é discutível a presença do narrador na crônica como gênero, porém parto aqui da premissa de que, a partir do momento que um autor se coloca em texto escrito, ocorre inevitavelmente o nascimento de um narrador. Ou seja, a partir do momento que o sujeito-observador se torna, através do processo criativo textual, também alvo da observação de leitores, sua identidade migra do físico para 
atento observador, cujos arredores nunca passam despercebidos. O narrador de Darío cita Fire Island, ilha que fica na costa de Long Island, sendo a última ilha de Nova Iorque que separa a Great South Bay do oceano Atlântico. ${ }^{14}$ Trata-se de um lugar muito frequentado pelos residentes de Nova Iorque para fins de lazer, tendo um grande número de resorts e sendo também um ponto turístico para aqueles que visitam a metrópole. Em sua ilha vizinha, Long Island, que separa Nova Iorque de Connecticut, estão os condados Queens e Brooklyn. Além dessas duas ilhas, Sandy Hook, também mencionada por Darío, consiste na península de Nova Iorque famosa por ter sido utilizada, principalmente, para fins militares - sendo um dos mais proeminentes pontos para proteção estadunidense de invasores.

A propósito, antes que fosse um país, foi dessa península, principalmente, que os britânicos se mobilizaram contra a antiga colônia estadunidense durante a Revolução Americana. O farol de Sandy Hook, que o narrador observa, é o mais antigo farol estadunidense (construído em 1763) ainda a ser utilizado - tendo a altura impressionante de 85 pés. ${ }^{15}$ Curiosamente, quando o narrador faz essa última referência, ele diz que é de lá, Sandy Hook, que zarpa o barco da sanidade - comentário que, poderíamos conjecturar, poderia servir de crítica para vários aspectos da história do país que ele observa com esse olhar que tanto julga. Nunca imaginaria Darío que, mais de cem anos depois da publicação desse seu texto, Sandy Hook seria conhecida devido ao "Massacre de Sandy Hook" (uma pesquisa rápida no google demonstra isso, já que primeiro vemos notícias sobre o caso para depois termos acesso à informações mais gerais sobre o lugar). Na manhã do dia 14/12/2012, Adam Lanza (20 anos), depois de assassinar a própria mãe com quatro tiros no rosto, invadiria a escola Sandy Hook Elementary School para matar a sangue frio vinte crianças e seis adultos - mais uma estória dessas que se repetem na terra das oportunidades. Se o barco da sanidade ainda não havia zarpado de Sandy Hook, o narrador de Darío parecia ciente que, cedo ou tarde, ele o faria.

A terceira categoria de referências levantada por Darío concerne aos aspectos culturais que ocupam esse espaço descrito por seu narrador. A concessionária italiana da Fiat é uma das primeiras dessas referências; tendo se firmado

\footnotetext{
o metafísico, subjetivando sua objetividade e se tornando, também, um personagem dos eventos que descreve. Literariamente, assim, o cronista estaria para o personagem-narrador - abstrato e impalpável.

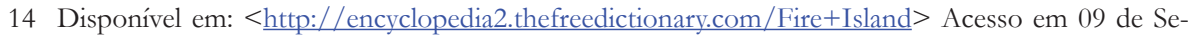
tembro de 2020.

15 Disponível em: < http://encyclopedia2.thefreedictionary.com/Sandy+Hook $>$ Acesso em 09 de Setembro de 2020.
} 
dentro do solo estadunidense também dentro do comércio de motores, tanques de guerra, tratores e aviões. Trata-se, na contemporaneidade, da quarta maior concessionária do mundo - atrás apenas da Volkswagen, da PSA e da Renault. ${ }^{16}$ Depois, o narrador também faria menção ao "Tio Samuel" - que resolvi manter Uncle Sam em minha tradução, não só para manter o ar estrangeiro como também prezar pela manutenção da analogia. Personificação do governo americano desde a Primeira Grande Guerra, a figura sempre esteve associada ao poderio militar do país, sua força enquanto império, e à importância de que a jovem nação que emergia da ex-colônia britânica seguisse as ordens e conselhos daquele "tio" - o qual convocava os estadunidenses durante a guerra para lutar "pela honra" da sua pátria. Como já alegado, algumas referências à construções específicas servem o propósito de reiterar essa sensação de pequenez do narrador frente àquele cenário sufocante. É esse o caso de sua menção ao Produce Exchange Building, um dos maiores prédios comerciais dos Estados Unidos - devido à sua arquitetura ele foi, em 1983, tombado no National Register of Historic Places. ${ }^{17}$ Outra construção humana de aspecto grandioso é a ponte de The Narrows, um estreito (pequena faixa de mar) que separa os distritos do Brooklyn e Staten Island em Nova Iorque. Feita em 1776, trata-se essa de uma construção bastante ambiciosa sendo, em seu tempo, a maior ponte suspensa do mundo - hoje continua sendo a maior desse tipo nos Estados Unidos. ${ }^{18}$

A Sociedade Nacional dos Filhos da Revolução Americana (S.A.R) também é mencionada pelo narrador. Trata-se de uma organização fraternal (algo como uma ONG) dos Estados Unidos, fundada em 1889 - ou seja, menos de dez anos antes da publicação do texto de Darío - na qual os associados advogam, lutam e propõe projetos em prol da independência de instituições Americanas, dos interesses nacionais e da manutenção do espírito de patriotismo. ${ }^{19}$ Quem vê traços de reacionarismo em tal descrição não se engana; os membros da ordem são em geral homens brancos que falam como se em lugar daqueles estadunidenses que serviram na Guerra da Revolução ou que, de alguma forma, estiveram

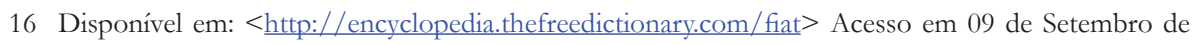
2020.

17 Disponível em: $<$ https://encyclopedia.thefreedictionary.com/Produce Exchange Building $>$ Acesso em 09 de Setembro de 2020.

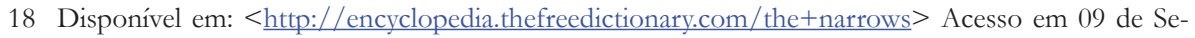
tembro de 2020.

19 Disponível em: < https://encyclopedia.thefreedictionary.com/SAR> Acesso em 09 de Setembro de 2020. 
envolvidos com o processo de independência dos Estados Unidos. As tradições, ideias e constituição do país são a bíblia de quem segue a ordem, sendo S.A.R a responsável pela criação, através de seus incansáveis esforços, dos feriados: Dia da Bandeira, e Dia da Constituição. Já que estamos a falar de história, é interessante notar que o narrador de Darío cita as gírias Yankee que, ao seu redor, ele escuta. Em geral, a palavra Yankee é usada para fazer referência às pessoas nativas da Nova Inglaterra e/ou à "não-americanos" (especialmente Britânicos). Uma hipótese para o surgimento da palavra é a pronúncia que os nativos americanos faziam da palavra English, que muito se assemelha a Yankee..$^{20}$ Trata-se de um termo pejorativo (principalmente depois de ser usado pelos confederados para designar os estadunidenses favoráveis à União), ainda que durante a Revolução os Ingleses tivessem orgulho de ser chamados assim. Gradativamente, referências populares em músicas, discursos etc. garantiram a manutenção do termo - sendo que ele aparece até mesmo em Cuba, após a revolução socialista, quando os revolucionários se dirigiam aos estadunidenses com mais hostilidade.

A quarta e última categoria que criei para separar as referências extratextuais feitas por Darío dizem respeito à um artifício muito comum para deixar claro o espaço onde se dá a narrativa em mãos dos leitores-alvo: o uso de estrangeirismos através de termos e/ou marcas de oralidade específicos. Palavras que possuem correspondentes em espanhol foram substituídas por palavras em inglês, às vezes com e às vezes sem aviso prévio. O observador chega em Manhattan em um "steamer" - ou seja, em um barco a vapor - que está prestes a atracar em uma "dock" - ou seja, numa doca (estrutura onde navios são removidos da água, sendo erguidos para que suas partes geralmente encobertas pela água sejam inspecionadas). Dentro desse "steamer" o narrador percebe a presença de um "clergyman" (um clérigo) e de uma menina vestindo um boné de "jockey" - que poderia, obviamente, ser traduzido por "jóquei", ainda que eu tenha preferido manter o estrangeirismo. O narrador de Darío escuta, entre as "slangs" que se proliferam ao seu redor, um "policemen" a dizer "all right" para uma velha "lady", assim como o jornaleiro gritando "intanrsooonwood!", ao que tenta vender para os passageiros do bonde os jornais Sun, World e Evening Telegram. Além do inglês, existe também o uso do francês no texto; para ser mais exato de uma estrofe completa de cinco versos de um poema de Leconte de Lisle (presente em Poèmes barbares, de 1862).

20 Disponível em: < http://encyclopedia2.thefreedictionary.com/yankee> Acesso em 09 de Setembro de 2020 . 
Trata-se esse, inclusive, do único momento em minha tradução no qual me dispus a adicionar duas notas do tradutor - uma para indicar de onde parece ter sido retirado o trecho, que não é referenciado no texto de Darío, e outra com a tradução proposta por ele. Assim como no original, disponibilizo em minha versão da crônica uma tradução abaixo do trecho do poema escrito por de Lisle. Apesar de, aparentemente, Darío (ou os editores/revisores do texto espanhol) não demonstrar muita preocupação com a forma poética da estrofe na tradução mais "literal" que se faz dela, como existe um padrão métrico, rítmico e de rimas no original, tentei recriá-la a partir desse padrão. Seria ele, para as rimas, a-b-b-a-b; e para o ritmo anapesto, com algumas variações (principalmente o uso de iambo ao início de cada verso). Com essa preocupação em mente, transformações mais radicais no sentido dos versos foram propostas. Segue o resultado desse intento, acompanhado de meus outros intentos - espero que a tradução satisfaça meus leitores brasileiros tanto quanto a leitura da crônica me satisfez.

\section{EDGAR ALLAN POE ${ }^{21}$ *ORIGINAL}

\section{EDGAR ALLAN POE ${ }^{22}$ *TRADUÇÃO}

En una mañana fría y húmeda llegué por primera vez al inmenso país de los Estados Unidos. Iba el steamer despacio, y la sirena aullaba roncamente por temor de un choque. Quedaba atrás Fire Island con su erecto faro; estábamos frente a Sandy Hook, de donde nos salió al paso el barco de sanidad. El ladrante slang yanqui sonaba por todas partes, bajo el pabellón de bandas y estrellas. El viento frío, los pitos arromadizados, el humo de las chimeneas, el movimiento de
Numa manhã fria e úmida eu cheguei, pela primeira vez, no imenso país dos Estados Unidos. Lento era o steamer, e a sirene uivava rouca temendo um choque. Ficava para trás Fire Island com seu alto farol; estávamos de frente a Sandy Hook, de onde zarpou o barco da sanidade. As rudes slangs Yankee soavam por todo o lado, sob a bandeira de estrelas e listras. $\mathrm{O}$ vento frio, o catarro dos apitos, a fumaça das chaminés, o movimento das máquinas, as ondas barrigudas daquele

21 Fragmento reproducido de Los Raros [1896], Madrid, Mundo Latino, s.d. Aunque Dário estuvo tres veces en Nueva York (1893, 1907 y 1914) la gran descripción de Manhattan la hace en el texto que dedica a Poe en Los Raros. El fragmento es el cruce entre la admiración y la crítica hacia a ciudad, los dos sentimientos constantes que recoge la escritura de Darío hacia Estados Unidos. [N. de la E.].

22 Fragmento retirado de Los Raros [1896], Madrid, Mundo Latino, s. d. Embora Darío tenha estado por três vezes em Nova Iorque (1893, 1907 e 1914), a sua grande descrição de Manhattan é feita no texto que dedica a Poe em Los Raros. O fragmento mostra seu ambíguo sentimento de admiração e de crítica acerca da cidade, coerente com muito daquilo que escreve Darío sobre os Estados Unidos. [N. E. - original]. 
las máquinas, las mismas ondas ventrudas de aquel mar estañado, el vapor que caminaba rumbo a la gran bahía, todo decía: all right. Entre las brumas se divisaban islas y barcos. Long Island desarrollaba la inmensa cinta de sus costas, y Staten Island, como en el marco de una viñeta, se presentaba en su hermosura, tentando al lápiz, ya que no, por falta de sol, a la máquina fotográfica. Sobre cubierta se agrupan los pasajeros: el comerciante de gruesa panza, congestionado como un pavo, con encorvadas narices israelitas; el clergyman huesoso, enfundado en su largo levitón negro, cubierto con su ancho sombrero de fieltro, y en la mano una pequeña Biblia; la muchacha que usa gorra de jockey, y que durante toda la travesía ha cantado con voz fonográfica, al son de un banjo; el joven robusto, lampiño como un bebé, y que, aficionado al box, tiene los puños de tal modo, que bien pudiera desquijar un rinoceronte de un solo impulso... En los Narrows se alcanza a ver la tierra pintoresca y florida, las fortalezas. Luego, levantando sobre su cabeza la antorcha simbólica, queda a un lado la gigantesca Madona de la Libertad, que tiene por peana un islote. De mi alma brota entonces la salutación:

"A ti, prolífica, enorme, dominadora. A ti, Nuestra Señora de la Libertad. A ti, cuyas mamas de bronce alimentan un sinnúmero de almas y corazones. A ti, que te alzas solitaria y magnífica sobre tu isla, levantando la divina antorcha. Yo te saludo al paso de mi steamer, prosternándome delante de tu majestad. ¡Ave: Good morning! Yo sé, divino icono, joh, magna estatua!, que tu solo nombre, el de la excelsa beldad que encarnas, ha hecho brotar estrellas sobre el mundo, a la manera del fiat del Señor. Allí están entre todas, brillantes sobre las listas de la bandera, las que iluminan el vuelo del mar de estanho, o vapor que caminhava na direção da grande baía, tudo dizendo: All Right. Em meio a bruma viam-se ilhas e barcos. Na costa de Long Island uma tira se dilatava e Staten Island, como o clímax de uma vinheta, demonstrava sua beleza, tentação para o lápis já que, por falta de sol, não podia tentar a câmera. No convés os passageiros se agrupam: o comerciante pançudo, inflado como um peru, de nariz torto, israelita; o clergyman ossudo, enfiado em seu imenso casaco preto, coberto por um largo chapéu de feltro e na mão uma pequena Bíblia; a menina com um gorro de jockey, que durante toda a travessia vem cantando com uma voz fonográfica, ao som de um banjo; o jovem robusto com a barba raspada tal qual bunda de bebê, aficionado por box, exibe punhos que poderiam, com um só golpe, levar a nocaute um rinoceronte... Em The Narrows dá pra ver a terra pitoresca e florida, as fortalezas. Logo depois, erguendo sob a cabeça sua tocha simbólica, ali está a gigantesca Madona da Liberdade, cuja base é uma ilhazinha. Da minha alma surge então a saudação:

"A ti, prolífica, enorme, dominadora. A ti, Nossa Senhora da Liberdade. A ti, cujos seios de bronze amamentam inúmeras almas e corações. A ti, que se levanta solitária e magnífica sobre sua ilha, erguendo sua tocha divina. Eu te saúdo de meu steamer, me prostrando diante de sua majestade. Ave! Good Morning! Eu sei, divino ícone, oh, magna estátua! O seu único nome, da beleza sublime que encarnas, vem fazendo brotar estrelas por todo o mundo, como o Fiat do Senhor. Lá estão entre todas, brilhantes sob as listas da bandeira, as que iluminam o voo da águia americana, dessa América 
águila de América, de esta tu América formidable, de ojos azules. Ave, Libertad, llena de fuerza; el Señor es contigo: bendita tú eres. Pero, ¿sabes?, se te ha herido mucho por el mundo, divinidad, manchando tu esplendor. Anda en la tierra otra que ha usurpado tu nombre, y que, en vez de la antorcha, lleva la tea. Aquélla no es la Diana sagrada de las incomparables flechas: es Hécate.»

Hecha mi salutación, mi vista contempla la masa enorme que está al frente, aquella tierra coronada de torres, aquella región de donde casi sentís que viene un soplo subyugador y terrible: Manhattan, la isla de hierro, Nueva York, la sanguínea, la ciclópea, la monstruosa, la tormentosa, la irresistible capital del cheque. Rodeada de islas menores, tiene cerca a Jersey; y agarrada a Brooklyn con la uña enorme del puente, Brooklyn, que tiene sobre el palpitante pecho de acero un ramillete de campanarios.

Se cree oír la voz de Nueva York, el eco de un vasto soliloquio de cifras. ¡Cuán distinta de la voz de París, cuando uno cree escucharla, al acercarse, halagadora como una canción de amor, de poesía y de juventud! Sobre el suelo de Manhattan parece que va a verse surgir de pronto un colosal Tío Samuel, que llama a los pueblos todos a un inaudito remate, y que el martillo del rematador cae sobre cúpulas y techumbres produciendo un ensordecedor trueno metálico. Antes de entrar al corazón del monstruo, recuerdo la ciudad, que vio en el poema bárbaro el vidente Thogorma:

Thogorma dans ses yeux vit monter des murailles De fer dont s'enroulaient des spirales des tours formidável, de olhos azuis. Ave, Liberdade, cheia de força; o Senhor é contigo; bendita és tu. Mas, sabe o que? Já te tens ferido muito pelo mundo, divindade, manchando o seu esplendor. Visitas a outra terra que te roubou o nome e que, em vez da tocha, ficou com o fogo. Aquela não é a Diana sagrada de incomparáveis flechas: é Hécate."

Feita a saudação, minha vista contempla uma enorme massa à frente, aquela terra coroada por torres, aquela região de onde quase se pode sentir um golpe dominante e terrível: Manhattan, a ilha de ferro, Nova Iorque, a sanguinária, a ciclópica, a monstruosa, a tempestuosa, a capital irresistível do cheque. Rodeada por ilhas menores, perto de Jersey; e agarrada a Brooklyn com a unha enorme da ponte, Brooklyn, que tem sobre o peito palpitante de aço um ramalhete de campanários.

Acredita-se ouvir a voz de Nova Iorque, o eco de um vasto solilóquio de números. Como difere da voz de Paris, quando imaginam ouvi-la, ao se aproximar, lisonjeira como uma canção de amor, de poesia e de juventude! Sobre o solo de Manhattan parece que vai surgir do nada um Uncle Sam colossal, convocando todos os povos para um leilão sem igual, onde o martelo do leiloeiro cai sobre os telhados e as cúpulas e gerando um trovão metálico ensurdecedor. Antes de entrar no coração do monstro, me lembro da cidade, que viu no bárbaro poema o vidente Thogorma:

Thogorma dans ses yeux vit monter des murailles De fer dont s'enroulaient des spirales des tours

23 Leconte de Lisle, em Poèmes barbares, 1862 [N.T.]. 
Et des palais cerclés d'airain sur des blocs lourds;

Ruche énorme, gébenne aux lúgubres entrailles

Oú s'engouffraint les Forts, princes des anciens jours.

[Thogorma vio con sus ojos construir las murallas

De hierro donde se envuelven los espirales de las torres

Y los palacios rodeados de bronce sobre pesados ladrillos;

Enorme colmena, gébenne en las lúgubres entrañas

Donde se devora a los Fuertes, príncipes de los viejos días]

Semejantes a los Fuertes de los días antiguos, viven en sus torres de piedra, de hierro y de cristal, los hombres de Manhattan.

En su fabulosa Babel, gritan, mugen, resuenan, braman, conmueven la Bolsa, la locomotora, la fragua, el banco, la imprenta, el dock y la urna electoral. El edificio Produce Exchange, entre sus muros de hierro y granito, reúne tantas almas cuantas hacen un pueblo... He allí Broadway. Se experimenta casi una impresión dolorosa; sentís el dominio del vértigo. Por un gran canal, cuyos lados los forman casas monumentales que ostentan sus cien ojos de vidrio y sus tatuajes de rótulos, pasa un río caudaloso, confuso, de comerciantes, corredores, caballos, tranvías, ómnibus, hombres-sandwichs vestidos de anuncios y mujeres bellísimas. Abarcando con la vista la inmensa arteria en su hervor continuo, llega a sentirse la
Et des palais cerclés d'airain sur des blocs lourds;

Ruche énorme, gébenne aux lúgubres entrailles

Oú s'engouffraint les Forts, princes des anciens jours. $^{23}$

[Thogorma com seus olhos viu crescer os muros

De ferro, onde se envolvem os pilares espiralados

Com palácios cercados por bronze em tijolos pesados;

Lar enorme, a torturar nossos seres escuros

Onde se devoram os fortes, reis dos tempos passados] $]^{24}$

Semelhantes aos Fortes dos tempos passados, vivem em seus pilares de pedra, ferro e cristal, os homens de Manhattan.

Em sua Babel fabulosa, gritam, mugem, ressoam, rugem, deixam comovida a Bolsa, a locomotiva, a forja, o banco, a imprensa, o dock e a urna eleitoral. O edifício Produce Exchange, entre seus muros de ferro e granito, reúne tantas almas quanto existe em um povo... Eis Broadway. Se passa por uma experiência quase dolorosa; sentes o domínio de vertigem. Por um grande canal, cujas laterais formam casas monumentais que ostentam seus cem olhos de vidro e suas tatuagens de rótulos, passa um rio caudaloso, confuso, de comerciantes, corretores, cavalos, bondes, ônibus, homens-sanduíches vestidos de anúncios e mulheres estupendas. Abarcando com essa vista a imensa artéria em contínuo pulsar, dá até

24 "Thogorma vio con sus ojos construir las murallas / De bierro donde se envuelven los espirales de las torres / Y los palacios rodeados de bronce sobre pesados ladrillos; / Enorme colmena, gébenne en las lúgubres entrañas / Donde se devora a los Fuertes, príncipes de los viejos dias" (DARÍO, 2013, p. 131). 
angustia de ciertas pesadillas. Reina la vida del hormiguero: un hormiguero de percherones gigantescos, de carros monstruosos, de toda clase de vehículos. El vendedor de periódicos, rosado y risueño, salta como un gorrión, de tranvía en tranvía, y grita al pasajero intanrsooonwoood!, lo que quiere decir, si gustáis comprar cualquiera de esos tres diarios, el Evening Telegram, el Sun o el World. El ruido es mareador y se siente en el aire una trepidación incesante; el repiqueteo de los cascos, el vuelo sonoro de las ruedas, parece a cada instante aumentarse. Temeríase a cada momento un choque, un fracaso, si no se conociese que este inmenso río que corre con una fuerza de alud, lleva en sus ondas la exactitud de una máquina. En lo más intrincado de la muchedumbre, en lo más convulsivo y crespo de la ola en movimiento, sucede que una lady anciana, bajo su capota negra, o una miss rubia, o una nodriza con su bebé, quiere pasar de una acera a otra. Un corpulento policeman alza la mano; detiénese el torrente; pasa la dama; jall right!

"Esos cíclopes...", dice Groussac; "esos feroces calibanes...", escribe Peladan. ¿'Tuvo razón el raro Sar al llamar así a estos hombres de la América del Norte? Calibán reina en la isla de Manhattan, en San Francisco, en Boston, en Washington, en todo el país. Ha conseguido establecer el imperio de la materia desde su estado misterioso con Edison, hasta la apoteosis del puerco, en esa abrumadora ciudad de Chicago. Calibán se satura de whisky, como en el drama de Shakespeare de vino; se desarrolla y crece; y sin ser esclavo de ningún Próspero, ni martirizado por ningún genio del aire, engorda y se multiplica. Su nombre es Legión. Por voluntad de Dios suele brotar de entre esos poderosos monstruos algún ser de superior pra sentir a angústia de certos pesadelos. Reina a vida de formigueiro: um formigueiro de gigantes cavalos percheron, de monstruosos caminhões, de todo o tipo de veículo. O jornaleiro, rosado e sorridente, salta como um pardal, de bonde em bonde, e grita aos passageiros intanrsooonwoood!, o que significa, se quiser pode comprar qualquer um desses três jornais, o Evening Telegram, o Sun ou o World. O ruído é estonteante e se sente no ar a trepidação incessante; o bater dos cascos, o rodar sonoro dos pneus, parecem aumentar a cada instante. Talvez se temesse um acidente, um fracasso, caso não se soubesse que esse imenso rio, que corre com a força de uma avalanche, carrega em suas ondas a precisão de uma máquina. No ponto mais claustrofóbico da multidão, no movimento mais convulsivo da mais elevada onda, acontece que uma velha lady, sob seu capuz preto, ou uma miss loira, ou uma babá com seu bebê, deseja se deslocar de uma calçada para outra. Um corpulento policeman ergue a mão; se interrompe a torrente; passa a dama; All Right!

"Esses ciclopes..." diz Groussac "Esses Calibãs ferozes...", escreve Peladan. Teve razão a estranha $S A R$ ao chamar assim esses homens da América do Norte? Calibã reina na ilha de Manhattan, em São Francisco, em Boston, em Washington, em todo o país. Conseguiu estabelecer o império da matéria desde seu surgimento com Edison, até a apoteose do porco, nesta esmagadora cidade de Chicago. Calibã se embriaga com uísque, assim como no drama de Shakespeare de vinho; se desenvolve e cresce; e sem ser escravo de qualquer Prospero, nem martirizado por qualquer gênio de ar, engorda e se multiplica. O seu nome é Legião. Pela vontade de Deus por vezes brotam por entre esses monstros poderosos algum ser de natureza 
naturaleza, que tiende las alas a la eterna Miranda de lo ideal. Entonces, Calibán mueve contra él a Sicorax, y se le destierra o se le mata. Esto vio el mundo con Edgar Allan Poe, el cisne desdichado que mejor ha conocido el ensueño y la muerte... mais elevada, que tende as asas da eterna Miranda do ideal. Então, Calibã se move contra Sycorax, para expulsá-la ou matá-la. Ele viu o mundo com Edgar Allan Poe, o cisne miserável que melhor conheceu o sonho e a morte...

\section{Referências bibliográficas}

ANTUNES, Antonio Lobo. O meu nome é legião. São Paulo: Alfaguara, 2009.

BÍBLIA. A. T. O evangelho segundo Marcos. In: BÍBLIA. Português. Bíblia sagrada: Antigo e Novo Testamento. Trad. João Ferreira de Almeida. Rio de Janeiro: Sociedade Bíblica do Brasil, 1966. pp. 678-686.

CANDIDO, Antonio. "A Vida ao Rés-do-Chão". In: CANDIDO, Antonio et al. A Crônica: O gênero, sua fixação e suas transformações no Brasil. Campinas: Editora Unicamp, 1992. pp. 13-22.

DARÍO, Ruben. Los raros. Buenos Aires: Letras libres, 1896.

. "Edgar Allan Poe." In: Viajes de un Cosmopolita Extremo. Buenos Aires: Fondo de Cultura Económica, 2013. pp. 129-133.

DE LISLE, Leconte. Poèmes barbares. Lyon: Librairie Alphonse Lemerre, 1862.

JOUVE, Vincent. Por que estudar literatura? Trad. Marcos Bagno e Marcos Marciolino. São Paulo: Parábola editorial, 2012.

LAZARO IGOA, Rosario; COSTA, Walter Carlos. "Edição e tradução nas crônicas brasileiras dos séculos XIX e XX: Entrevista com John Gledson.” In: Cadernos de Tradução, v. 36, n. 2 (2016): pp. 311-329.

MONTALDO, Graciela. “Guía Rubén Darío.” In: DARÍO, Rubén. Viajes de un Cosmopolita Extremo. Buenos Aires: Fondo de Cultura Económica, 2013. pp. 11-52.

PAIVA, Daniel. "Fronteira e contacto em O meu nome é Legião." In: Estudos geográficos de Lisboa, v. 42, n. 1 (2013): pp. 183-201.

PIGLIA, Ricardo. El Último Lector. Buenos Aires: Debolsillo, 2014.

SHAKESPEARE, William. The Tempest. London: Penguin popular classics, 1992.

VILLORO, Juan. "La crónica, ornitorrinco de la prosa". La Nación, Buenos Aires, 22 de Janeiro de 2006, Suplemento Cultura. 